\title{
Sustainability of vector control strategies in the Gran Chaco Region: current challenges and possible approaches
}

\author{
Ricardo E Gürtler
}

Laboratory of Eco-Epidemiology, Facultad de Ciencias Exactas y Naturales, Universidad de Buenos Aires, Buenos Aires, Argentina

Sustainability has become a focal point of the international agenda. At the heart of its range of distribution in the Gran Chaco Region, the elimination of Triatoma infestans has failed, even in areas subject to intensive professional vector control efforts. Chagas disease control programs traditionally have been composed of two divorced entities: a vector control program in charge of routine field operations (bug detection and insecticide spraying) and a disease control program in charge of screening blood donors, diagnosis, etiologic treatment and providing medical care to chronic patients. The challenge of sustainable suppression of bug infestation and Trypanosoma cruzi transmission can be met through integrated disease management, in which vector control is combined with active case detection and treatment to increase impact, cost-effectiveness and public acceptance in resource-limited settings. Multi-stakeholder involvement may add sustainability and resilience to the surveillance system. Chagas vector control and disease management must remain a regional effort within the frame of sustainable development rather than being viewed exclusively as a matter of health pertinent to the health sector. Sustained and continuous coordination between governments, agencies, control programs, academia and the affected communities is critical.

Key words: ecosystem health - sustainability - integrated vector control - development - community participation insecticide resistance - pyrethroids

\section{Sustainability and the context}

Sustainability has become a focal point of the international agenda. The last 50 years have seen emerging concerns about the links between a growing world population that needs to be fed and supported; development; climate change; depletion of fisheries and other renewable and non-renewable (oil) natural resources worldwide and (re)-emergence of pathogens, some with pandemic potential. There is a clear link between health and sustainable development (Boischio et al. 2009). Reflecting these concerns, sustainability science is becoming a distinct research field with multiple contributing scientific disciplines engaged in inter, intra and transdiciplinary research (Rapport 2007).

The Earth's human population has seen unprecedented growth during the XX century (Cohen 1995). In 1900, slightly before Carlos Chagas discovered a new disease entity caused by the new parasite Trypanosoma cruzi, the world population was 1.7 billion and most people lived in rural areas (Cohen 1999, 2003). Much of the world population lived in poverty, a situation that continued through the XX century. Infectious diseases were rampant in Chagas' time and the mean life expectancy was about 30 years. Exploitation of natural resources and expansion

Financial support: NIH (R01 TW05836 del FIC and NIEHS), Agencia Nacional de Promoción Científica y Técnica, Universidad of Buenos Aires, Fundación Mundo Sano, IDRC, TDR/WHO Corresponding author: gurtler@ege.fcen.uba.ar

Received 19 May 2009

Accepted 26 June 2009 of the railroad system gave birth to new settlements and to the propagation of triatomine bugs and T. cruzi. By the turn of the XXI century, the world population had increased to six billion and nearly half of these people lived in cities (Cohen 1999, 2003). The mean life expectancy reached 76 years in rich countries and 63 years in the poor countries. Despite a four-fold increase in the average annual gross domestic product per person during the XX century, economic inequality increased and there were 2.8 billion people living in poverty (on $<\$ 2$ per day) in 1998 (Kate \& Parris 2003). Chagas disease, a poverty-related and poverty-promoting disease, still remains an important and neglected tropical disease. In 2002, the burden of Chagas disease in Latin America was estimated to amount to as much as 2.7 times the joint burden of malaria, schistosomiasis, leishmaniasis and leprosy, accounting for 670,000 disability-adjusted life years through its impact on worker productivity, premature disability and death (World Bank 1993, WHO 2004).

Current projections show additional changes ahead. The world population is projected by this year's United Nations projections to grow from the current 6.8-7 billion early in 2012, and to surpass nine billion by 2050 . Most of the additional 2.3 billion people will enlarge the population of developing countries and will be distributed among those older than 15 years. The rural-to-urban exodus observed during the XX century will continue and perhaps $60 \%$ of the world population will be urbanites by 2030 (Kates \& Parris 2003); 90\% of the population in Latin America is likely to live in cities. Changes in all facets of human life (environment, technology etc.) will certainly affect the current distribution of Chagas disease in several directions that are hard to anticipate. 
In the report Our Common Future, the World Commission on Environment and Development (1987) recognised that global environmental problems resulted from both the South's enormous poverty and the North's unsustainable consumption and production rates. Sustainability indicates the ability to sustain or a state that can be maintained at a certain level. With roots in the exploitation of renewable natural resources, sustainability has been used to express the levels of harvest in agriculture, fisheries and sport hunting that are compatible with the capacity of the ecosystem to restore them. Sustainable development is "development that meets the needs of the present without compromising the ability of future generations". Defining sustainability is ultimately a social choice about what to develop, what to sustain and for how long (Parris \& Kates 2003).

Parris and Kates (2003) developed a framework for characterising the sustainability transition in several matters of development and environment. They distinguished between goals, indicators, targets, trends and driving forces. Goals are qualitative statements about objectives (e.g., reducing infant mortality). Indicators are quantitative measures selected to assess progress toward or away from a stated goal (e.g., infant mortality rate). Targets (or more explicitly, the "target value of an indicator") are quantitative values of indicators of the progress made toward a goal at a specified time or within a certain timeframe (e.g., a $20 \%$ reduction in current infant mortality rates within the next 5 years). Trends are changes in the values of an indicator over time (e.g., infant mortality rates declined from 1 to $0.5 \%$ over the last decade). Driving forces are the processes that modify trends and our ability to meet agreed upon targets (e.g., vaccine coverage and nutrition influence infant mortality rates). This framework is especially relevant to the control initiatives that seek to suppress transmission of T. cruzi in the Gran Chaco and elsewhere, and it calls for clear definitions, quantitative data, quality of reporting and systematic assessment.

The concept of resilience has emerged as a critical concept in complex, adaptive systems in a range of disciplines. Complex systems consist of many diverse and autonomous, but interrelated and interdependent components, linked through many interconnections (García 2006). Complex systems exhibit properties that emerge from the interaction of their parts and which cannot be predicted from the properties of the individual parts. Resilience may be defined as the capacity of a system to tolerate disturbances while retaining its structure and function (Fiksel 2006). Resilience has also been defined as recovery from perturbations. Resilient systems are able to survive, adapt and grow in the face of uncertainty and unforeseen disruptions.

\section{Chagas disease vector control}

Prevention of vector-borne transmission of T. cru$z i$ has almost exclusively relied upon the application of insecticides since gamma-hexachlorocyclohexane $(\gamma-\mathrm{HCH})$ was proven effective against triatomine bugs in the late 1940s (Dias \& Pellegrino 1948, Romaña \& Abalos 1948). Directed efforts toward large-scale hous- ing improvement as a means of preventing or reducing bug infestations in rural areas have been rather very unusual (e.g., Venezuela).

Nation-wide triatomine control programs started in a few countries in the $1960 \mathrm{~s}$, but only reached the regional scale in the 1990s (Dias 2007). Traditionally, vector control programs had a centralised and vertical structure borrowed from malaria and yellow fever programs, with a specific and time-delineated goal (i.e., vector eradication or elimination) and a highly motivated organisation of professional spray workers. Vector elimination entails the complete suppression of a vector species in a geographically defined region in the absence of control actions (i.e., a stable equilibrium point), barring reintroduction from external sources. Programs seeking vector elimination put very little emphasis on continuous vector surveillance once the goal is attained. Horizontal control programs specifically train local human resources (local householders, community leaders, primary health care agents) to spray and conduct surveillance actions, with the purported aims of increasing coverage and sustainability while decreasing operational costs (Segura 2002). The goal of vector control is to reduce infestations to levels below which the risk of parasite transmission is negligible. There is no endpoint for vector control actions and an unstable equilibrium may be reached; if control actions are suspended, the system tends to return to a prior state. Vector elimination and control also differ in the quantity and quality of human and financial resources needed as well as in the degree of long-term commitment that states and affected communities must endorse. A clear definition of the ultimate goals of the vector control program will also help to assess whether the program has been successful or not.

Progress in Chagas disease prevention gained momentum during the 1980s and 1990s through large-scale vector control actions and screening of blood donors. In the Southern Cone countries of South America, a regional intergovernmental control program was launched in 1991 with the original objectives of eliminating all domestic and peridomestic populations of the main vector Triatoma infestans (responsible for approximately $2 / 3$ of all human cases of $T$. cruzi in Latin America) and transmission via blood transfusion by the year 2000 (Schmunis et al. 1996, Dias et al. 2002, Silveira et al. 2002). Other regional control initiatives covering the Andean countries (1997), Central America (1997) and the Amazon Basin (2004) were launched later with similar objectives. Disease control programs reduced the geographic range and infestation prevalence of major triatomine vectors and increased routine screening of blood donors. These efforts led to the interruption of transmission mediated by T. infestans in Uruguay, Chile, Brazil, Eastern Paraguay, and a few provinces in Argentina, and significant improvements in Southern Peru (Dias et al. 2002, Silveira et al. 2002, Levy et al. 2006, Schofield et al. 2006). In Central America, infestations with Triatoma dimidiata have been strongly reduced and Rhodnius prolixus seems to have been eliminated from large parts of the previously endemic regions (Yamagata \& Nakagawa 2006). 
These positive trends prompted some people to advance (in 1996) the premature notion that Chagas disease was "a disease whose days are numbered" (WHO 1996). Subsequently, the initial 2000 target for the Southern Cone Initiative and the 2005 target for interruption of transmission of Chagas disease set by the World Health Assembly in 1998 (Resolution WHA.51.14) and echoed by others (WHO 2002) were not met, nor is the 2010 target for elimination endorsed by the WHO in mid-2007 (WHO 2007) likely to be met (Reithinger et al. 2009). Active vector-borne transmission still persists in vast areas of Argentina, El Salvador and Colombia, among others, and several countries (Mexico, Peru, Colombia, Panama and Costa Rica) have no national programs for the control of Chagas disease vectors or have yet to implement them effectively (Schofield et al. 2006). Above all, these control programs need to be sustained at appropriate levels of effectiveness for extended time periods until the goals are achieved. Again, this is ultimately a social choice.

Many examples illustrate the need for a renewed emphasis on sustainability. Recrudescence of vector-borne transmission occurred in previously "controlled" areas in Argentina as soon as the intensity of residual insecticide spraying declined (Segura 2002, Gürtler 2007, Gürtler et al. 2007, Vazquez-Prokopec et al. 2009). The emergence of pyrethroid resistance in T. infestans in the late 1990s further complicated the scenario. High-risk settings such as those in Bolivia and Southern Peru depended on timelimited foreign loans to sustain the vigorous insecticide campaigns developed during the current decade. Other primary vectors of $T$. cruzi with widespread sylvatic foci (e.g., $R$. prolixus, T. dimidiata, Panstrongylus megistus, Triatoma brasiliensis and others) tend to invade and colonise human habitations and therefore are less vulnerable to standard insecticide campaigns than $T$. infestans (Diotaiuti et al. 2000, Sanchez-Martin et al. 2006). There still are millions of chronically infected people, who will need medical treatment for decades to come (Dias et al. 2002). The frequency of oral outbreaks of Chagas disease in the Amazon Basin through ingestion of contaminated food has increased dramatically and gained much visibility over the last decade (Coura et al. 2002, Coura 2007). Fortunately, this evidence has served to raise awareness that "it is premature to believe that Chagas disease is conquered" (Schofield et al. 2006).

At the heart of its range of distribution in the Gran Chaco ecoregion, the elimination of $T$. infestans has failed, even in areas subjected to intensive, professional vector control efforts for reasons that remain poorly understood (Gürtler 2007, Gürtler et al. 2007). At the outset of the Southern Cone Initiative, the elimination of T. infestans was deemed feasible because the available evidence indicated that it lacked sylvatic foci except in the Andean Valleys in Bolivia, it was highly susceptible to modern pyrethroids, and had little genetic variability from which insecticide resistance could emerge. However, surveys conducted in the Bolivian and Argentine Chaco (Noireau et al. 2000, 2005, Ceballos et al. 2009) and in Chile (Bacigalupo et al. 2006) contradicted the first assumption. T. infestans was shown to have a rich genetic variability through its distribution range (Bar- gues et al. 2006, Perez de Rosas et al. 2007, Piccinali et al. 2009) and insecticide resistance emerged in Northwestern Argentina and Bolivia in the late 1990s (Picollo et al. 2005, Toloza et al. 2008). Moreover, recent evidence shows the emergence of another focus of pyrethroid resistance in $T$. infestans, causing control failures in Chaco province, Northeast Argentina (JM Gurevitz et al., unpublished observations). Despite these findings, the progress achieved in Chagas disease vector control and interruption of transmission in several areas is indisputable when measured over several decades (Segura et al. 2000). Progress has been much less impressive in parts of the Chaco over the last decade (Gürtler 2007). The issue is whether such progress can be achieved and sustained in the problem areas for extended periods of time. To achieve the stated goal of sustained interruption of transmission, we need to identify the causal chains to current problems, design viable solutions in the face of uncertainty and field-test them rigorously at various spatial scales. Identifying the factors that determine the persistence of T. infestans in the Gran Chaco has been identified as a top priority of the Southern Cone Initiative in its 15th Meeting held in Brasilia, in 2006.

\section{The Gran Chaco}

The Gran Chaco (from chacu, hunting grounds) is a 1.3 million $\mathrm{km}^{2}$ ecoregion that extends primarily over Argentina (62\%), Paraguay (25\%) and Bolivia (12\%) (The Nature Conservancy et al. 2005). The average human population density is very low $(<5$ inhabitants per $\mathrm{km}^{2}$ ), numbering approximately five million people. Villages or settlements are sparsely distributed and have irregular access by dirt roads. Aboriginal populations suffering from Chagas disease and other infectious diseases barely survive in Eastern Bolivia, Western Paraguay and Northern Argentina. At least 13 aboriginal groups with different languages reside in the western Paraguayan Chaco (Rojas de Arias 2003).

The Gran Chaco includes the humid and the dry Chaco, with wide climatic gradients and particular geological characteristics that have created a rich environmental and biological diversity. The vegetation is a mosaic of hardwood forests, grasslands and savannas, swamps and salt flats. Temperatures range from $-10^{\circ} \mathrm{C}$ in the south to $49^{\circ} \mathrm{C}$ in the north. Annual rainfall decreases from $1,300 \mathrm{~mm}$ in the east to $350 \mathrm{~mm}$ in the west. This feature largely limited agriculture in the west and favoured desertification in some areas. Rural houses are typically built of mud-and-thatch or mud-and-stick materials and constitute a suitable habitat for $T$. infestans. Peridomestic structures housing domestic animals also constitute suitable habitats for $T$. infestans and other triatomines such as Triatoma guasayana, Triatoma garciabesi and Triatoma sordida (Canale et al. 2000). Such peridomestic structures are numerous in many areas of the Argentine Chaco, but not in the Bolivian and Paraguayan Chaco.

Natural hardwood forests in the Chaco have been overexploited and pastures overgrazed during the XX century. These processes, jointly with periodic slashand-burn to facilitate agriculture and cattle-ranching, led to unproductive scrub associated with a subsistence 
economy based on raising goats, logging, production of charcoal, hunting or fishing (Bucher \& Schofield 1981). Changes in land use, value and ownership jointly with the rapid expansion of large-scale soybean crops in the Eastern Chaco and in other sections in Salta and Paraguay over the 1990s and 2000s have caused a large impact on the landscape, irreversible degradation of natural forests and a significant biodiversity loss. These changes also affected the socioeconomic structure of campesino populations and frequently led to displacement of rural residents and social unrest. Despite several rural development programs, rural poverty remains high. From $50-70 \%$ of the rural population in the Argentine Chaco has unsatisfied basic needs and these figures may reach up to $76 \%$ in Bolivia. Water shortages limit the development of large areas in the Chaco and increases poverty, according to the Human Development Report published by the United Nations Development Program in 1997.

The common characteristics shared by the Argentine, Bolivian and Paraguayan Chaco are (i) a mostly underdeveloped rural setting characterised by a subsistence economy with high levels of poverty and substandard housing, which determine a high burden of infectious diseases, very low population density and high dispersion of villages and house compounds; (ii) high prevalence of infestation with $T$. infestans and human infection with T. cruzi, with frequent occurrence of myocardiopathy or megasyndromes attributable to Chagas disease (the maternal seroprevalence of $T$. cruzi was up to $20 \%$ in some Argentine provinces during the current decade, with an estimated frequency of occurrence of congenital cases surpassing 1,000 per year and vector-borne acute cases of Chagas disease are stably notified to the surveillance system, reviewed in Gürtler 2007) and (iii) scarce presence of national and provincial governments in rural areas, combined with residual vector control services with very limited or declining operational capacity in many districts. Notable exceptions to this regional pattern are the strengthened provincial vector control programs of La Rioja and Santiago del Estero (Argentina) during the last few years. The abovementioned factors determined that vector surveillance has been irregular, less intense than in other areas, costly and unsustainable when measured over the last 50 years. The Chagas disease transmission system has a large capacity to recover (i.e., resilience) from the time-limited interventions represented by residual insecticide spraying campaigns.

\section{Limitations of current vector control tactics}

Why do vector elimination efforts fail in the Chaco? Unlike with malaria and dengue, the exclusive reliance on insecticides is perhaps a hallmark of Chagas disease vector control and one of the major weaknesses of the strategy used so far. This article offers a non-exhaustive list of points as an incentive for further elaboration and discussion toward finding appropriate solutions:

Tools, actors and procedures are not perfect - Pyrethroid insecticides, professional spray teams and affected householders who assume vector control operations (Vazquez-Prokopec et al. 2009) are each less than 100\% effective under the harsh working conditions in the Chaco. There are no silver bullets to suppress a highly adapted vector species such as $T$. infestans, which still maintains viable sylvatic foci in remote forest areas without human presence. The notion that $T$. infestans would be a straightforward control target outside of its apparent centre of origin in the Andean valleys of Bolivia (because of its assumed non-autochthonous status) is called into question by empirical evidence collected by vector control programs and researchers in Chaco over several decades. The Southern Cone Initiative recently concluded that traditional vector control actions conducted in the Gran Chaco have not been as effective as elsewhere and need to be revised (http://www.paho.org/english/ad/ dpc/cd/dch-incosur-xv.htm). Insecticide coverage and vector surveillance have frequently been incomplete in space and time (Gürtler et al. 2007, Vazquez-Prokopec et al. 2009). Repeated insecticide spraying campaigns to compensate for human mistakes and coverage gaps (i.e., 2 or more rounds of blanket insecticide spraying over 1-2 years) are prohibitively expensive and unsustainable.

Pyrethroids have dominated the vector control scene since the mid-1980s. Pyrethroids have proven much more effective in human habitations than in peridomestic outbuildings housing domestic animals and various species of triatomine bugs (Gürtler et al. 2004, Cecere et al. 2006a). Lack of recognition of this limitation implied recurrent cycles of reinfestation, (re-)spraying, increased cost and frustration. The insecticidal activity of pyrethroids is inversely temperature-dependent and is reduced by marked exposure to sunlight and high temperatures, which induce rapid photolysis of pyrethroid molecules in peridomestic structures such as corrals or chicken coops. Furthermore, the effectiveness of pyrethroids decreases with the abundance of $T$. infestans per site before spraying domestic or peridomestic habitats (Gürtler et al. 2004, Cecere et al. 2006a). Residual peridomestic foci cause early domestic reinfestation. A resurgence of peridomestic populations of $T$. infestans after residual spraying with pyrethroid insecticides has frequently been reported (Cecere et al. 2006a, b, Porcassi et al. 2006) in the absence of any insecticide resistance. The elimination of $T$. infestans from the Gran Chaco requires a greater intensity and quality of control actions than those that have been used so far. However, the sustained use of pyrethroids over the last two decades may have opened the way to the emergence of insecticide resistance in $T$. infestans, a process whose rate of occurrence is expected to increase in the future if the frequency of insecticide spraying is increased and sustained vector elimination is not achieved. The emergence in 2008 of another focus of pyrethroid-resistant T. infestans causing control failures in Pampa del Indio (Chaco Province) constitutes the first such focus recorded in Northeastern Argentina (JM Gurevitz et al., unpublished observations).

The world is not flat - The quote is borrowed from economist Pankaj Ghemawat's book (2007) and stands in opposition to the notion of increasing homogeneity in global economic markets. The complex system repre- 
sented by Chagas disease includes several overlapping, interacting domains relevant to infestation, transmission, disease and control: the biophysical, geographic, cultural, administrative/political and economic domains. Several sources of heterogeneity (environmental, demographic, spatio-temporal, insecticide resistance) may determine the occurrence of hot and cold-spots of infestation, infection, infectiousness and parasite transmission (Cecere et al. 2006b, Cardinal et al. 2007, Gürtler et al. 2007). In traditional practice, however, vector and disease control actions have been homogeneous. In many of these activities there is a dangerous inclination to apply panaceas (i.e., a single solution to many problems regardless of the circumstances) (Anderies et al. 2007, Ostrom 2007). "Effort(s) to impose a standard 'optimal' solution (are) 'the' problem rather than 'the' solution." (Ostrom 2007). Plausible solutions for a problem are dependent on the temporal and spatial scale. In the particular case of Chagas disease, the five domains mentioned above modify the expected outcome of the standard solution (i.e., residual insecticide spraying) in different directions.

The basic spatial heterogeneity of Chagas disease vector control status is reflected in areas under effective, sustained surveillance coexisting with areas where control actions have been irregular over time, and areas under a persisting reinfestation problem where symptomatic Chagas acute cases (i.e., the tip of the iceberg) have been notified in Northern Argentina (Gürtler 2007). Sparse populations with difficult access are expected to have much larger infection prevalence than more accessible and populated districts with more capacity to demand vector control actions and health services. Such heterogeneities in the distribution of infestation and infection remain hidden in the nation or province-wide averages usually reported by disease control programs. Such grand averages are mostly based on biased, convenience sampling surveys and lack additional measures of precision.

There is nothing permanent except change (Heraclitus) - And changes are hard to anticipate and to deal with. Recurrent instability at political, social and economic levels pose major threats to disease control programs in the regions most affected by Chagas disease. Frequent changes in health authorities and heads of vector control programs are the rule, whereas a long-term state policy on Chagas disease control running through different administrations is the exception. Political and economic support for Chagas control programs wanes soon after signs of success appear. The growing decentralisation of health services to provincial and municipal levels added the unmet challenge of coordinating efforts among districts differing in infestation, control status, resources and priorities and between national, provincial and municipal public health levels (Schmunis \& Dias 2000, Yadón et al. 2007). The structure of vector control programs ranged from strongly centralised in Paraguay and Chile, to partially decentralised in Argentina (since the 1980s), to fully decentralised in Bolivia and in Brazil since the 2000s. As vector control programs became overburdened by the (re-) emergence or expansion of dengue, malaria and other scourges in the region, fewer resources were applied to Chagas disease vector control. One such case is the widespread dengue outbreak in Argentina in 2009; all triatomine vector control actions were halted.

Drastic changes in the natural landscape, especially through intense deforestation, habitat degradation and mismanagement of deforested areas may favour increased house invasion by sylvatic triatomines and sylvatic $T$. cruzi strains, as well as the spread of domestic triatomine species by human migration in search of better living conditions. Migration from rural to urban environments, often to poor housing in slums, creates conditions for urbanisation of $T$. infestans and transmission of $T$. cruzi, as recently seen in the peripheries of large cities such as Arequipa in Peru (Levy et al. 2006), Cochabamba in Bolivia (Medrano-Mercado et al. 2008) and in several small towns in Santiago del Estero (Añatuya, Tintina etc.) and La Rioja (Olta) in Argentina over the 1990s. This rural-to-urban migration is expected to continue over the next decades. The urbanisation of $T$. infestans in the capital city of San Juan (Argentina), where it infests palm trees, abandoned buildings and terraces with pigeon nests throughout the city, was observed in the 1990s (Vallvé et al. 1996) and still is a matter of current concern and intense combat (Carrizo Páez et al. 2008). The finding of a female specimen of $T$. infestans and eggs in Comodoro Rivadavia (southern Chubut, Argentina) in mid-2007 (RV Piccinali, DM Canale et al., unpublished observations), outside of its geographic range and presumably brought by immigrants, is another reminder that vector surveillance and control must remain a regional enterprise.

\section{Current goals and possible approaches}

There is a wide consensus on the goals to be pursued in the foreseeable future: (i) to minimise the burden of disease, through reducing the prevalence and incidence of human infection with $T$. cruzi and by reducing the incidence of disease and the disease-specific death rate, and (ii) to eliminate the implicated vector species throughout most or all of its geographic range, if feasible, or keep its abundance below specified levels not compatible with parasite transmission. If the goal is vector control, then long-term surveillance is indispensable and two key issues emerge: sustainability and cost-effectiveness. Regardless of the ultimate goal, there are concerns related to the potential emergence of secondary vector species that currently are not control targets (T. sordida, T. guasayana etc.). However, even in areas where the abundance of $T$. infestans was reduced to the verge of elimination and there was intense house invasion by $T$. sordida and $T$. guasayana before and after residual insecticide spraying, persistent domestic colonisation has not been recorded in the Gran Chaco (Vazquez-Prokopec et al. 2008, Gurevitz et al., unpublished observations).

The current emphasis on sustainability is based on the rather erratic trajectory of control efforts recorded in the Gran Chaco in the past. The experience in Argentina offers several lessons for the future (Gürtler 2007). Contrary to several far-sighted predictions, the elimination 
of T. infestans from its entire geographic range has not been achieved and may not be feasible in the most affected regions in the current political, social, economic and health context, or in the context projected for the next 5-10 years. Therefore, a shift toward recurrent control actions through an established vector surveillance system needs to be favoured in many situations. Perhaps the main characteristic common to the entire Gran Chaco is rapid house reinfestation after community-wide residual spraying with insecticides. The underlying causes of such reinfestations are a matter of current research efforts in a multisite study conducted simultaneously in the Argentine, Bolivian and Paraguayan Chaco. There is a pressing need to design a cost-effective, sustainable surveillance system for a large, underdeveloped territory with a sparsely distributed population.

Long-term sustainable control of Chagas disease in the Chaco is feasible through a multifaceted, integrated, intersectoral approach discussed in more detail elsewhere (Gürtler et al. 2007). Current challenges to the prevention and control of Chagas disease are manifold, but they are tractable (Tarleton et al. 2007, Reithinger et al. 2009). In the Chaco, vector control programs need to be strengthened in various dimensions (staff, vehicles etc.) and provided with information technology and training in data management and analysis. Rural housing improvement and replacement of peridomestic enclosures for animals with appropriate designs and materials would render them less susceptible to triatomine colonisation. These interventions of a more permanent nature will contribute to long-term sustainability by lessening the dependence on insecticides. Achieving these aims requires linking heretofore isolated governmental agencies in charge of rural development, housing, education and health at national and provincial levels (Singer \& Caldas de Castro 2007). Chagas vector control and disease management must remain a regional effort within the frame of sustainable development rather than being viewed exclusively as a matter of health pertinent to the health sector. Sustained and continuous coordination between governments, agencies, control programs, academia and the affected communities is crucially needed.

Vector control programs rarely have included other relevant actors in a consistent fashion over the process of developing and implementing a disease control strategy. Potential actors that may play a significant role include the local education system; non-governmental organisations with various interests (environmental, ethnic, religious); governmental agencies linked to rural development; universities and research institutes; municipalities, and the affected individuals, households and communities. Intersectoral cooperation has not been exploited to its full potential. Multi-stakeholder involvement may add sustainability and resilience to the surveillance system (Bazzani et al. 2004). Community participation plays a crucial role in long-term vector surveillance and control, but it is no spontaneous panacea. It thus needs to be nurtured, promoted and well-supervised.

The challenge of sustainable suppression of bug infestation and T. cruzi transmission can be met through integrated disease management, in which vector control is combined with active case detection and treatment to increase impact, cost-effectiveness and public acceptance in resource-limited settings (Gürtler et al. 2008). The lack of health education and access of the rural poor to diagnosis and treatment with benznidazole or nifurtimox in many areas implies that the affected communities are unaware of the actual extent of the Chagas disease burden affecting them, its potential health consequences and the available means to combat the threat. Roots of the neglect may also be traced to the limited political and economic power of the vulnerable populations affected by the disease.

\section{ACKNOWLEDGEMENTS}

This article is based on published papers and on extensive discussions with MC Cecere, JE Cohen, L Diotaiuti, U Kitron, F Noireau, R Reithinger, A Rojas de Arias, CJ Schofield, EL Segura, C Spillmann, R Tarleton J. Urbina, GM Vázquez-Prokopec and other colleagues whom I want to thank for their generosity. Part of the article was motivated by a meeting organized by Fondation Mérieux at its Conference Center in Veyrier du Lac, France, in May 2008.

\section{REFERENCES}

Anderies JM, Rodríguez AA, Janssen MA, Cifdaloz O 2007. Panaceas, uncertainty, and the robust control framework in sustainability science. Proc Natl Acad Sci USA 104: 15194-15199.

Bacigalupo A, Segura JA, García A, Hidalgo J, Galuppo S, Cattan PE 2006. First finding of Chagas disease vectors associated with wild bushes in the Metropolitan Region of Chile. Rev Med Chil 134: $1230-1236$.

Bargues MD, Klisiowicz DR, Panzera F, Noireau F, Marcilla A, Perez R, Rojas MG, O’Connor JE, González-Candelas F, Galvão C, Jurberg J, Carcavallo RU, Dujardin JP, Mas-Coma S 2006. Origin and phylogeography of the Chagas disease main vector Triatoma infestans based on nuclear rDNA sequences and genome size. Infect Genet Evol 6: 46-62.

Bazzani R, Noronha L, Sánchez A 2004. An ecosystem approach to human health: building a transdisciplinary and participatory research framework for the prevention of communicable diseases. Available from: http://www.globalforumhealth.org/forum8/ forum8cdrom/OralPresentations/Sanchez $\% 20 \mathrm{Bain} \% 20 \% 20 \mathrm{~F} 8$ 165.doc. [Accessed 23 September 2007].

Boischio A, Sánchez A, Orosz Z, Charron 2009. Health and sustainable development: challenges and opportunities of ecosystem approaches in the prevention and control of dengue and Chagas disease. Cad Saude Publica 25 (Suppl. 1): S149-S154.

Bucher EH, Schofield CJ 1981. Economic assault on Chagas disease. New Scientist 29: 321-325.

Canale DM, Cecere MC, Chuit R, Gürtler RE 2000. Peridomestic distribution of Triatoma garciabesi and Triatoma guasayana in North-West Argentina. Med Vet Entomol 14: 383-390.

Cardinal MV, Lauricella MA, Marcet PL, Orozco MM, Kitron U, Gürtler RE 2007. Impact of community-based vector control on house infestation and Trypanosoma cruzi infection in Triatoma infestans, dogs and cats in the Argentine Chaco. Acta Trop 103: 201-211.

Carrizo Páez R, Pickenhayn J, Carrizo Páez M 2008. Chagas urbano en San Juan. Diagnóstico, revisión y propuesta para un sistema integrado de ataque. Rev Argent Cardiol 76: 480-487.

Ceballos LA, Piccinali RV, Berkunsky I, Kitron U, Gürtler RE 2009. First finding of melanic sylvatic Triatoma infestans (Hemiptera: Reduviidae) in the Argentine Chaco. J Med Entomol, in press. 
Cecere MC, Vazquez-Prokopec GM, Ceballos LA, Gurevitz JM, Zárate JE, Zaidenberg M, Kitron U, Gürtler RE 2006a. Comparative trial of the effectiveness of pyrethroid insecticides against peridomestic populations of Triatoma infestans in Northwestern Argentina. J Med Entomol 43: 902-909.

Cecere MC, Vazquez-Prokopec GM, Gürtler RE, Kitron U 2006b. Reinfestation sources for Chagas disease vector, Triatoma infestans, Argentina. Emerg Infect Dis 12: 1096-1102.

Cohen JE 1995. How many people can the Earth support?, WW Norton \& Company, New York, $532 \mathrm{pp}$.

Cohen JE 1999. Population and planet: the twentieth century and the twenty-first. Harvard Magazine 102: 38-40.

Cohen JE 2003. Human population: the next half century. Science 302: 1172-1175.

Coura JR 2007. Chagas disease: what is known and what is needed - A background article. Mem Inst Oswaldo Cruz 102 (Suppl. I): 113-122.

Coura JR, Junqueira AC, Fernandes O, Valente SA, Miles MA 2002. Emerging Chagas disease in Amazonian Brazil. Trends Parasitol 18: 171-176.

Dias E, Pellegrino J 1948. Alguns ensaios com o "Gammexane" no combate aos transmissores da doença de Chagas. Bras Med 62: $185-191$.

Dias JCP 2007. Southern Cone Initiative for the elimination of domestic populations of Triatoma infestans and the interruption of transfusion Chagas disease: historical aspects, present situation and perspectives. Mem Inst Oswaldo Cruz 102 (Suppl. I): 11-18.

Dias JCP, Silveira AC, Schofield CJ 2002. The impact of Chagas disease control in Latin America: a review. Mem Inst Oswaldo Cruz 97: 603-612.

Diotaiuti L, Faria Filho O, Carneiro FCF, Dias JCP, Pires HHR, Schofield CJ 2000. Aspectos operacionais do controle do Triatoma brasiliensis. Cad Saude Publica 16: 7-14.

Fiksel J 2006. Sustainability and resilience: toward a systems approach. Sustainability: Science, Practic, \& Policy 2: 14-21.

García R 2006. Sistemas complejos. Conceptos, método y fundamentación epistemológica de la investigación interdisciplinaria, Gedisa, Barcelona, $200 \mathrm{pp}$.

Gürtler RE 2007. Eco-epidemiología regional de la transmisión vectorial: Enfermedad de Chagas en el Gran Chaco. In La enfermedad de Chagas. A la puerta de los 100 años del conocimiento de una endemia americana ancestral. Balance y futuro, 19092006. Chagas, hacia el Siglo XXI. AC Silveira (ed.), Organización Panamericana de la Salud-Fundación Mundo Sano, Buenos Aires, p. 137-156.

Gürtler RE, Canale DM, Spillmann C, Stariolo R, Salomón OD, Blanco S, Segura EL 2004. Effectiveness of residual spraying with deltamethrin and permethrin on peridomestic populations of Triatoma infestans in rural western Argentina: a district-wide randomized trial. Bull World Health Organ 82: 196-205.

Gürtler RE, Diotaiuti L, Kitron U 2008. Chagas disease: 100 years since discovery and lessons for the future. Int $J$ Epidemiol 37: 698-701.

Gürtler RE, Kitron U, Cecere MC, Segura EL, Cohen JE 2007. Sustainable vector control and management of Chagas disease in the Gran Chaco, Argentina. Proc Natl Acad Sci USA 104: 16194-16199.

Kates RW, Parris TM 2003. Long-term trends and a sustainability transition. Proc Natl Acad Sci USA 100: 8062-8067.
Levy MZ, Bowman NM, Kawai V, Waller LA, Cornejo del Carpio JG, Cordova Benzaquen E, Gilman RH, Bern C 2006. Periurban Trypanosoma cruzi-infected Triatoma infestans, Arequipa, Peru. Emerg Infect Dis 12: 1345-1352.

Medrano-Mercado N, Ugarte-Fernandez R, Butrón V, Uber-Busek S, Guerra HL, Araújo-Jorge TC, Correa-Oliveira R 2008. Urban transmission of Chagas disease in Cochabamba, Bolivia. Mem Inst Oswaldo Cruz 103: 423-430.

Noireau F, Flores R, Gutierrez T, Abad-Franch F, Flores E, Vargas F 2000. Natural ecotopes of Triatoma infestans dark morph and other wild triatomines in the Bolivian Chaco. Trans $R$ Soc Trop Med Hyg 94: 23-27.

Noireau F, Rojas Cortez MG, Monteiro FA, Jansen AM, Torrico F 2005. Can wild Triatoma infestans foci in Bolivia jeopardize Chagas disease control efforts? Trends Parasitol 21: 7-10.

Ostrom E 2007. Going beyond panaceas. Proc Natl Acad Sci USA 104: 11181-15187.

Parris TM, Kates RW 2003. Characterizing a sustainability transition: goals, targets, trends and driving forces. Proc Natl Acad Sci USA 100: 8068-8073.

Pérez de Rosas AR, Segura EL, García BA 2007. Microsatellite analysis of genetic structure in natural Triatoma infestans (Hemiptera: Reduviidae) populations from Argentina: its implication in assessing the effectiveness of Chagas' disease vector control programmes. Mol Ecol 16: 1401-1412.

Piccinali RV, Marcet PL, Noireau F, Kitron U, Gürtler RE, Dotson EM 2009. Genetic variability, population structure and phylogeography of Argentinian and Bolivian Triatoma infestans populations based on COI. J Med Entomol 46: 796-809.

Picollo MI, Vassena C, Santo Orihuela P, Barrios S, Zaidenberg M, Zerba E 2005. High resistance to pyrethroid insecticides associated with ineffective field treatments in Triatoma infestans (Hemiptera: Reduviidae) from Northern Argentina. J Med Entomol 42: 637-642.

Porcasi X, Catala SS, Hrellac H, Scavuzzo MC, Gorla DE 2006. Infestation of rural houses by Triatoma infestans (Hemiptera: Reduviidae) in southern area of Gran Chaco in Argentina. J Med Entomol 43: 1060-1067.

Rapport DJ 2007. Sustainability science: an ecohealth perspective. Sustainability: Science, Practic, \& Policy 2: 77-84.

Reithinger R, Tarleton RL, Urbina JA, Kitron U, Gürtler RE 2009. Eliminating Chagas disease: challenges and a roadmap. $\mathrm{Br} \mathrm{Med}$ J 338: 1044-1047.

Rojas de Arias A 2003. Control y Vigilancia de Chagas con la participación comunitaria de etnias indígenas: Una perspectiva de la situación, In XII Reunión Intergubernamental INCOSUR/Chagas, Santiago, Chile, p. 120-125.

Romaña C, Abalos JW 1948. Acción del "Gammexane" sobre los triatomideos. "Control" domiciliario. An Inst Med Regional Tucumán 2: 95-106.

Sanchez-Martin MJ, Feliciangeli MD, Campbell-Lendrum D, Davies CR 2006. Could the Chagas disease elimination programme in Venezuela be compromised by reinvasion of houses by sylvatic Rhodnius prolixus bug populations? Trop Med Int Health 11: 1585-1593.

Schmunis GA, Dias JCP 2000. Health care reform, decentralization, prevention and control of vector-borne diseases. Cad Saude Publica 16: 117-123.

Schmunis GA, Zicker F, Moncayo A 1996. Interruption of Chagas' disease transmission through vector elimination. Lancet 348: 1171. 
Schofield CJ, Jannin J, Salvatella R 2006. The future of Chagas disease control. Trends Parasitol 22: 583-588.

Segura EL 2002. El control de la Enfermedad de Chagas en la República Argentina. In AC Silveira, El control de la Enfermedad de Chagas en los paises del Cono Sur de América. Historia de una Iniciativa Internacional. 1991/2001, OPAS, Universidade Federal do Triângulo Mineiro, Uberaba, p. 45-108.

Segura EL, Cura EN, Sosa Estani S, Andrade J, Lansetti JC, de Rissio AM, Campanini A, Blanco SB, Gürtler RE, Alvarez M 2000 Long-terms effects of a nation-wide control program on the seropositivity for Trypanosoma cruzi infection in young men from Argentina. Am J Trop Med Hyg 62: 353-362.

Silveira AC, Rojas de Arias, A, Segura E, Guillén G, Russomando G, Schenone H, Pinto Dias JC, Valdes Padilla J, Lorca M, Salvatella R 2002. El control de la Enfermedad de Chagas en los paises del Cono Sur de América. Historia de una Iniciativa Internacional. 1991/2001, OPAS, Universidade Federal do Triângulo Mineiro, Uberaba, p. 316 pp.

Singer BH, Caldas de Castro M 2007. Bridges to sustainable tropical health. Proc Natl Acad Sci USA 104: 16038-16043.

Tarleton RL, Reithinger R, Urbina JA, Kitron U, Gürtler RE 2007. The challenges of Chagas disease - grim outlook or glimmer of hope. PLoS Medicine 4: 1852-1857.

The Nature Conservancy (TNC), Fundación Vida Silvestre Argentina (FVSA), Fundación para el Desarrollo Sustentable del Chaco (DeSdel Chaco) y Wildife Conservation Society Bolivia (WCS) 2005. Evaluación Ecorregional del Gran Chaco Americano/ Gran Chaco Americano Ecoregional Assessment. Buenos Aires. Fundación Vida Silvestre Argentina. Available from: http://www. vidasilvestre.org.ar/descargables/bosques selvas/chaco/dossier. pdf. [Accessed June 12, 2009).

Toloza AC, Germano M, Cueto GM, Vassena C, Zerba E, Picollo MI 2008. Differential patterns of insecticide resistance in eggs and first instars of Triatoma infestans (Hemiptera: Reduviidae) from
Argentina and Bolivia. J Med Entomol 45: 421-426.

Vallvé SL, Rojo H, Wisnivesky-Colli C 1996. Urban ecology of Triatoma infestans in San Juan, Argentina. Mem Inst Oswaldo Cruz 91: 405-408.

Vazquez-Prokopec GM, Cecere MC, Kitron U, Gürtler RE 2008. Spatiotemporal patterns of reinfestation by Triatoma guasayana (Hemiptera: Reduviidae) in two rural communities of Northwestern Argentina. Med Vet Entomol 22: 273-282.

Vazquez-Prokopec GM, Spillmann C, Zaidenberg M, Kitron U, Gürtler RE 2009. Cost-effectiveness of vector control strategies against Triatoma infestans in rural northwestern Argentina. PLoS Negl Trop Dis 3: e363.

WHO - World Health Organization 1996. Chagas disease: a disease whose days are numbered, Division of Control of Tropical Diseases, Geneva, p. 1-16.

WHO - World Health Organization 2002. Control of Chagas disease. World Health Organ Tech Rep Ser 905: 82-83.

WHO - World Health Organization 2004. World Health Report 2004 Changing History. Geneva, World Health Organization, 2004. Available from: http://www.who.int/whr/2004/en/.

WHO - World Health Organization 2007. New global effort to eliminate Chagas disease. Partners set out strategy against the 'kissing bug' disease. Available from: http://www.who.int/mediacentre/ news/releases/2007/pr36/en/index.html.

World Bank 1993. World Development Report. Investing in Health. Oxford University Press, New York, 348 pp.

Yadón ZE, Gürtler RE, Tobar F, Medici AC 2007. Decentralization and Management of Communicable Disease Control in Latin America. Pan American Health Organization, Buenos Aires. Available from: http://www.paho.org/English/ad/dpc/cd/res-descentralizacion.htm.

Yamagata Y, Nakagawa J 2006. Control of Chagas disease. Adv Parasitol 61: 130-165. 